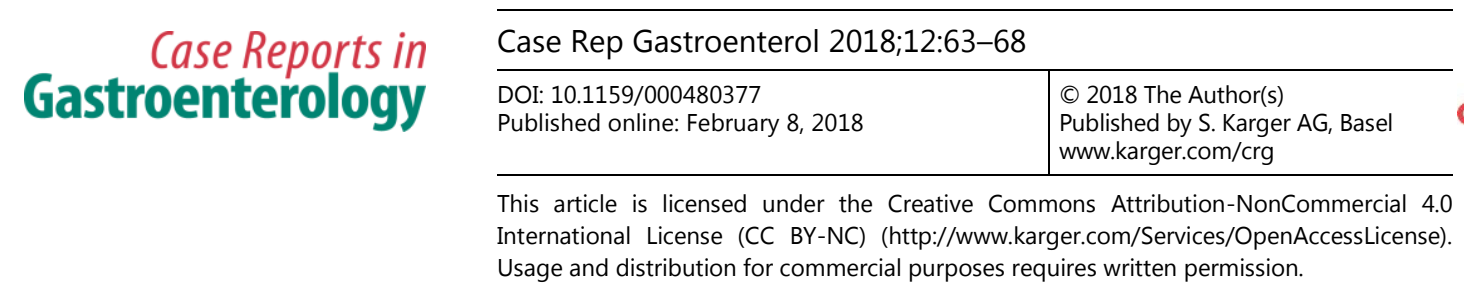

\title{
Ileum Histoplasmosis Mimicking Intestinal Tuberculosis and Crohn's Disease
}

\author{
Xin-Bo Ai ${ }^{a}$ Zhen-Jiang Wang ${ }^{\mathrm{a}}$ Qi-Chao Dong ${ }^{\mathrm{b}}$ Xu Lin ${ }^{\mathrm{b}}$ \\ Yu-Ping Chen ${ }^{a}$ Fei-Yue Gong ${ }^{a}$ Hui Liang ${ }^{b}$ \\ ${ }^{a}$ Department of Gastroenterology, Jinan University Zhuhai Hospital, Zhuhai, China; \\ ${ }^{b}$ Department of General Surgery, Jinan University Zhuhai Hospital , Zhuhai, China
}

\section{Keywords}

Ileum histoplasmosis · Intestinal tuberculosis · Crohn's disease

\begin{abstract}
Gastrointestinal histoplasmosis (GIH) without pulmonary and bone marrow involvement is very rare worldwide. It can be misdiagnosed as intestinal tuberculosis or Crohn's disease. There are just few case reports of GIH in patients with a positive HIV antibody test. Here, we report a patient who presented to our hospital with repeated intestinal obstruction. The suspicious diagnosis was intestinal tuberculosis or Crohn's disease due to unspecific clinical manifestations and radiologic images. Our patient's HIV antibody test was negative. She had no medical prescriptions. Therefore, our differential diagnosis needed to include ileum histoplasmosis besides intestinal lymphoma, intestinal tuberculosis, and Crohn's disease. Finally, the patient was diagnosed with ileum histoplasmosis due to surgical resection. It is important to be aware of potential infectious diseases, such as ileum histoplasmosis, when making a differential diagnosis. Moreover, surgical resection might be the final approach for smallintestine stricture with fibrosis.

(C) 2018 The Author(s)

Published by S. Karger AG, Basel
\end{abstract}




\section{Case Reports in Gastroenterology}

Case Rep Gastroenterol 2018;12:63-68 DOI: $10.1159 / 000480377$

(C) 2018 The Author(s). Published by S. Karger AG, Basel www.karger.com/crg

Ai et al.: Ileum Histoplasmosis Mimicking Intestinal Tuberculosis and Crohn's Disease

\section{Introduction}

Histoplasmosis is the most common endemic fungal infection in the United States [1]. Gastrointestinal histoplasmosis (GIH) is an uncommon disease with variable manifestations. $\mathrm{GIH}$ occurs due to hematogenous seeding as a result of mediastinal involvement. We need to differentiate gastrointestinal malignancies, inflammatory bowel disease, and intestinal tuberculosis due to unspecific manifestations. There are some case reports of GIH in the world, especially for immunosuppressed patients, the terminal ileum is the most common site of the small intestine with manifestations of ulcerations [2,3]. The etiology of histoplasmosis remains unknown. Some experts postulate that numerous histiocytes might not successfully kill the organism, the "carrier" state could be activated or irritated, which can cause proliferation of macrophages and potential dissemination under some circumstances; others presume that a transient immune deficiency or even a concomitant infection may play an important role in the development of histoplasmosis [4].

Here, we present a rare case of ileum histoplasmosis which was quite hard to differentiate from Crohn's disease and intestinal tuberculosis but without immune deficiency disease.

\section{Case Presentation}

A 50-year-old woman has suffered from repeated abdominal pain for 6 years. She had had a history of lung tuberculosis 10 years ago; consequently, she had received standard anti-tuberculosis chemotherapy for 9 months. The patient presented with acute lower right abdominal pain for 1 day due to intestinal obstruction proved with plain abdominal radiography. She had no fever, no cough, and no weight loss. Physical examination revealed mild tenderness of the right lower quadrant abdomen. Barium enema showed filling defects of the ileum (Fig. 1). Blood analysis showed a white blood cell count of $7.5 \times 10^{9} / \mathrm{L}$ and her Creactive protein level was $8 \mathrm{mg} / \mathrm{L}$. Chest X-ray revealed pulmonary scars. Bowel thickening (approximately $8.5 \mathrm{~mm}$ ), distal bowel dilation, and comb sign were seen on small bowel CT (Fig. 2). Colonoscopy was performed and returned without ulcers or nodularities. A purified protein derivative test revealed $15 \mathrm{~mm}$ of induration, and T-SPOT was positive. Furthermore, her HIV antibody test was negative. Chest contrast-enhanced CT showed pulmonary scar proliferation without active findings. Her intestinal obstruction was worsening with exclusive nutritional support treatment.

We held a multiple-discipline workshop involving a senior surgeon, gastroenterologist, radiologist, and pathologist. Fibrosis of the local small bowel was observed, and all experts reached the consensus that laparoscopic resection was indicated in this patient due to poor outcome of conservative therapy. Informed consent for surgical resection was obtained from the patient. The surgical specimen showed severe fibrosis and stenosis of $6 \mathrm{~cm}$ in length, the maximum depth of the lesion was $1.8 \mathrm{~cm}$, additional to multiple cobblestone appearances (Fig. 3). Microscopically, these lesions consisted of granuloma and numerous macrophages. Hematoxylin and eosin staining and immunohistochemistry with periodic acid-Schiff revealed budding forms of histoplasma capsulatum within the macrophages (Fig. 4). Ileum histoplasmosis was diagnosed by the senior pathologist. No postoperative complications were seen. 


\section{Discussion}

GIH is uncommon in the world. Hertan et al. [5] reported a 37-year-old man with duodenal histoplasmosis with no evidence of pulmonary and bone marrow involvement. It is really rare that the thickening of the bowel could cause obstructive symptoms mimicking Crohn's disease and malignancy [6]. Our patient presented with abdominal pain, ileum stricture, and a history of lung tuberculosis. There was no evidence of lung and bone marrow involvement. The suspicious diagnosis was intestinal tuberculosis or Crohn's disease. However, definite diagnosis was ileum histoplasmosis due to surgical indication. However, the causes of GIH are still unknown yet. Some causes are extremes of age, immunosuppression, idiopathic $\mathrm{CD}_{4}$ lymphocytopenia, Job's syndrome, and biologic agents like infliximab [7], others are co-existing infections [4].

Our patient had a history of lung tuberculosis, and the surgical specimen showed terminal ileum histoplasmosis. We believe that this may be a case of co-existing infection of tuberculosis and histoplasmosis. Gastroenterologists need to be aware of the differential diagnosis of GIH, because it can mimic inflammatory bowel disease, intestinal tuberculosis, and intestinal lymphoma - especially in patients who are about 50 years old. The prognosis seems much better after local resection. We need large-scale clinical research in the future.

\section{Statement of Ethics}

Written informed consent was obtained from the patient, and permission from the Institute's Ethics Committee was obtained.

\section{Disclosure Statement}

The authors have no conflicts of interest to disclose.

\section{References}

1 Goodwin RA, Des Prez RM: Could that influenza-like illness be histoplasmosis? J Respir Dis 1983; $11 ; 19-21$.

2 Lee KR, Lin F: Gastrointestinal histoplasmosis, roentgenographic, clinical and pathologic correlation. Am J Gastroenterol 1975;63:255-265.

-3 Sturim HJ, Kouchoukos NT, Ahlvin RC: Gastrointestinal manifestations of disseminated histoplasmosis. Am J Surg 1965;110:435-440.

4 Goodvin RA, Shapiro JL, Thurman GH, et al: Disseminated histoplasmosis: clinical and pathologic correlations. Medicine 1980;59:1-33.

5 Hertan H, Nair S, Arguello P: Progressive gastrointestinal histoplasmosis leading to colonic obstruction two years after initial presentation. Am J Gastroenterol 2001;96:221-222.

-6 Cimpaneniv D, Lopresti P, Lavelanet M, et al: Gastrointestinal histoplasmosis in HIV infection. Two cases of colonic pseudocancer and review of literature. Am J Gastroenterol 1994;89:129-131.

7 Kahi CJ, Wheat JR, Allen SD, et al: Gastrointestinal histoplasmosis. Am J Gastroenterol 2005;100: 220-231. 


\begin{tabular}{|c|c|c|}
\hline \multirow{2}{*}{$\begin{array}{r}\text { Case Reports in } \\
\text { Gastroenterology }\end{array}$} & \multicolumn{2}{|c|}{ Case Rep Gastroenterol 2018;12:63-68 } \\
\hline & DOI: 10.1159/000480377. & $\begin{array}{l}\text { (c) } 2018 \text { The Author(s). Published by S. Karger AG, Basel } \\
\text { www.karger.com/crg }\end{array}$ \\
\hline
\end{tabular}

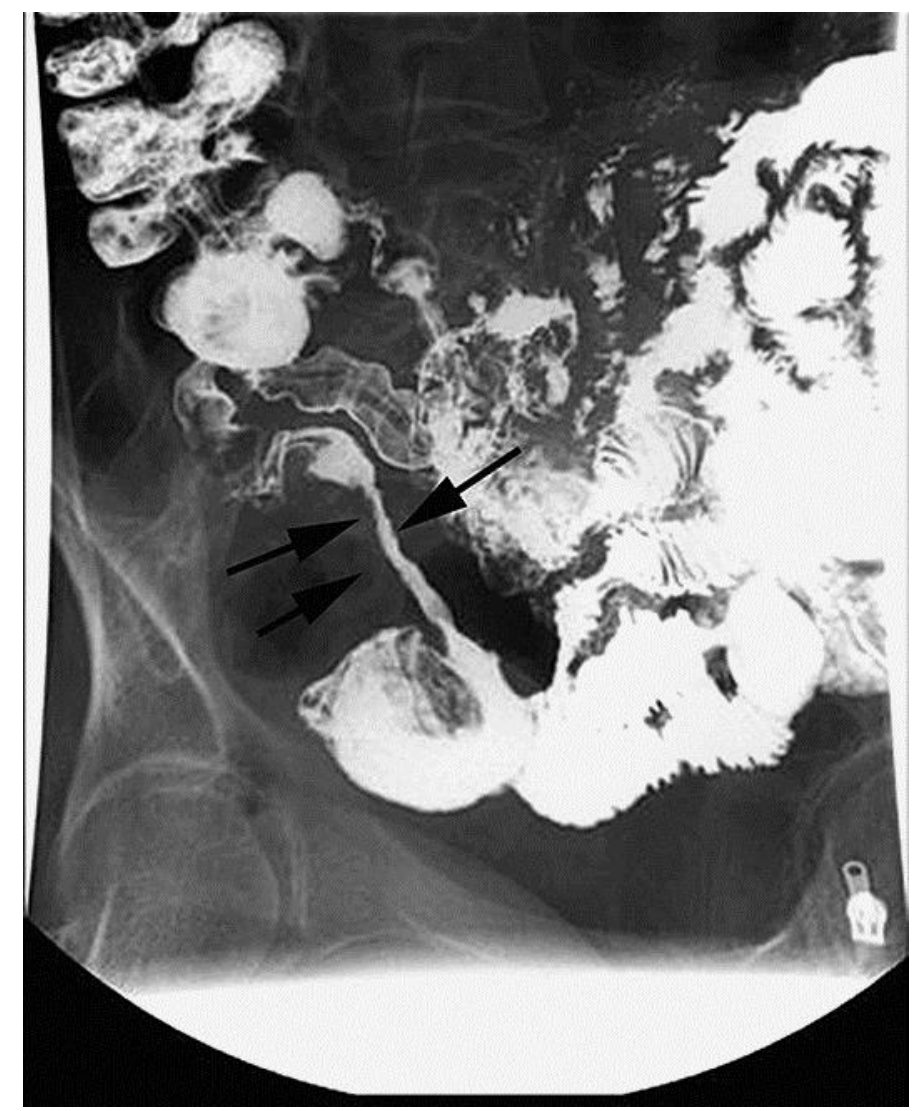

Fig. 1. Barium enema showing filling defects and a partial ileum stricture (arrows). 


\section{Case Reports in Gastroenterology

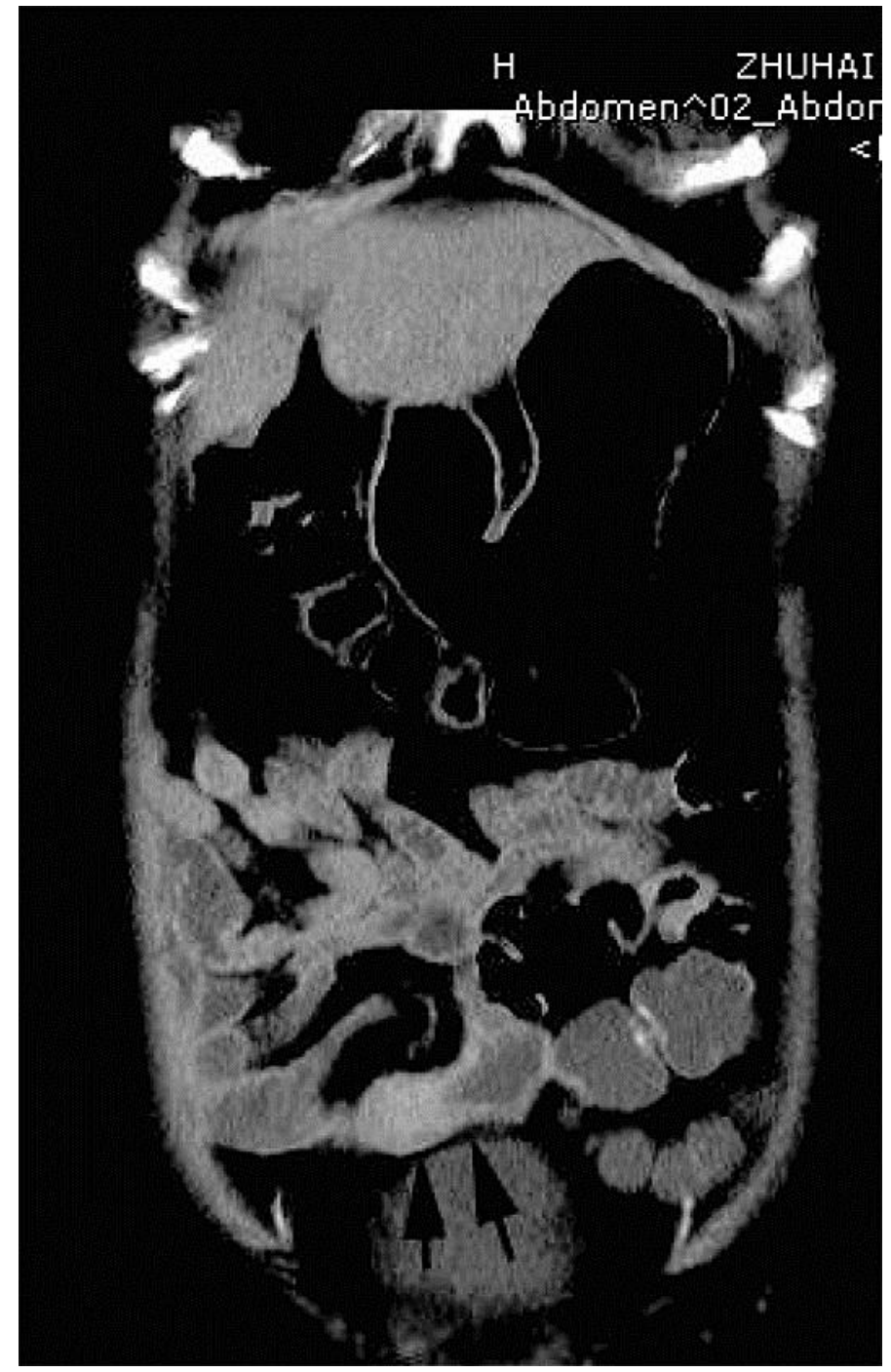

Fig. 2. Small-bowel CT demonstrating bowel thickening, distal bowel dilation, and "comb" sign (arrows). 


\begin{tabular}{|c|c|c|}
\hline \multirow{2}{*}{$\begin{array}{r}\text { Case Reports in } \\
\text { Gastroenterology }\end{array}$} & \multicolumn{2}{|c|}{ Case Rep Gastroenterol 2018;12:63-68 } \\
\hline & DOI: $10.1159 / 000480377$ & $\begin{array}{l}\text { (O) } 2018 \text { The Author(s). Published by S. Karger AG, Basel } \\
\text { www.karger.com/crg }\end{array}$ \\
\hline
\end{tabular}

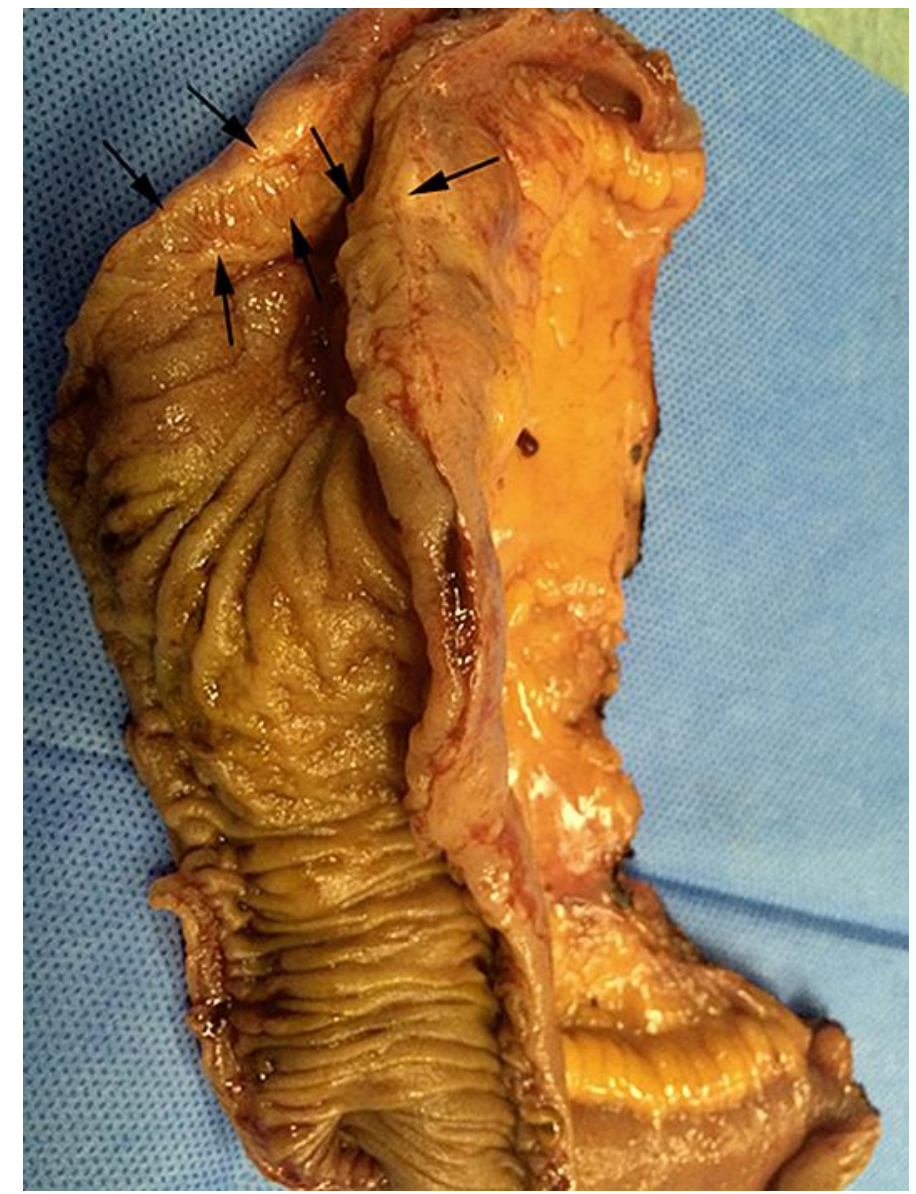

Fig. 3. Surgical specimen showing ileum fibrosis and stenosis, and multiple cobblestone appearances (arrows).

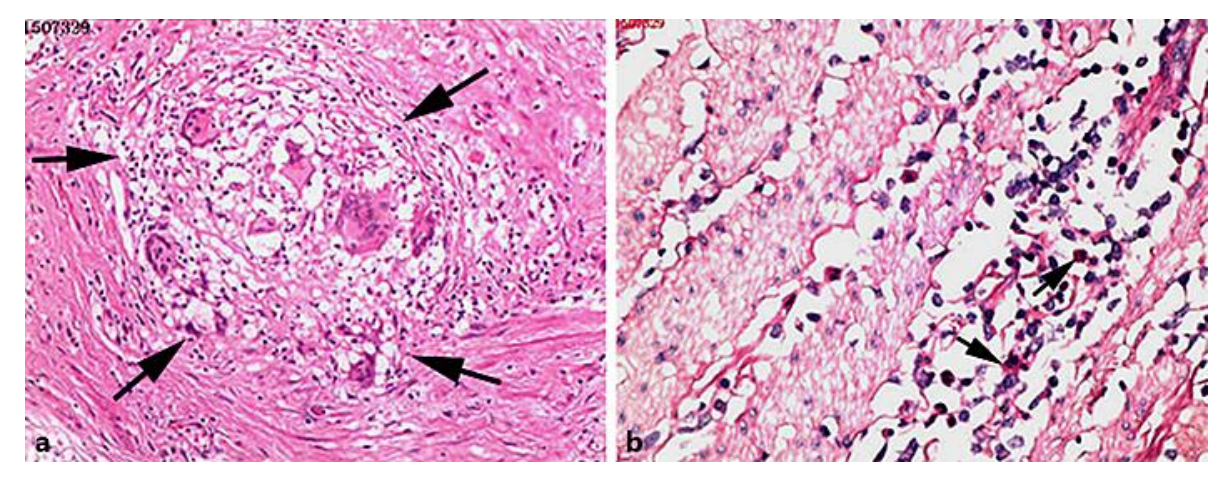

Fig. 4. a Diffused lymphohistiocytic infiltration and well-formed granulomas were observed microscopically $(\mathrm{HE} \times 20$ ) (arrows). b Periodic acid-Schiff staining revealed budding forms of histoplasma capsulatum within macrophages $(\mathrm{HE} \times 40)$ (arrows). 